Enrique Álvarez Conde

Catedrático de Derecho Constitucional

\title{
El Gobierno en funciones
}

SUMARIO: I. LA NOCIÓN DE GOBIERNO EN FUNCIONES. II. ANÁLISIS DE DERECHO COMPARADO. III. REGULACIÓN DEL GOBIERNO EN FUNCIONES. IV. LA LEGISLACIÓN AUTONÓMICA. V. LA LEY DEL GOBIERNO: EL ARTÍCULO 21.

\section{LA NOCIÓN DE GOBIERNO EN FUNCIONES}

Resulta evidente que el Gobierno se ha convertido en el centro de la acción política del Estado contemporáneo, más allá de las funciones enumeradas en los propios textos constitucionales, y a pesar de las importantes competencias atribuidas a otros órganos constitucionales y de los procesos de integración supranacional en que estamos inmersos. La aceptación del fortalecimiento del Ejecutivo y la proclamación del Estado social y democrático de Derecho implica un cambio sustancial en las relaciones entre el Gobierno y otros órganos constitucionales, no sólo el Parlamento, implicando un mayor margen de autonomía de aquél, que tratar de conjugar el principio de estabilidad gubernamental y el necesario control parlamentario a través del principio de representación popular.

Por otra parte, este protagonismo del Gobierno para dirigir la acción política del Estado se produce en todos los países, con independencia de su propio sistema de gobierno, si bien es lícito afirmar que la posición constitucional de aquél es distinta en un 
sistema parlamentario que en un sistema presidencialista, ya que la necesidad de contar con la confianza parlamentaria se convierte en una condición de existencia de aquél y no de éste. En general, el Gobierno aparece en los textos constitucionales como un órgano colegiado, jurídicamente homogéneo y titular de unas funciones escuetamente definidas, pero extensamente virtualizadas.

Hasta la aprobación de la Ley 50/1997, de 27 de noviembre, del Gobierno, la regulación de la organización y funcionamiento del mismo se encontraba en textos legales diversos, algunos de ellos de carácter preconstitucional (como el Decreto de 26 de julio de 1957, por el que se aprueba el texto refundido de la Ley de régimen jurídico de la Administración del Estado) y, por ello, no del todo coherentes con los principios materiales y organizativos que inspiran la Constitución Española de 1978. Incluso, es necesario afirmar que la aprobación de la referida Ley no ha agotado la materia, pues se hace necesario revisar $y$, en su caso, reformar, toda una serie de disposiciones de carácter reglamentario que regulan aspectos no sujetos al principio de reserva de ley en esta materia.

En nuestro país, la Constitución configura un sistema de gobierno parlamentario de carácter racionalizado, donde el Monarca carece de poderes de decisión y donde se trata de combinar el principio de estabilidad gubernamental con el control parlamentario del Gobierno, aunque quizá lo más característico de nuestro sistema político sea que el Gobierno no va a depender tanto de la confianza del Parlamento como de la figura de su Presidente, cuya intervención en la composición del mismo es total, pues se parte del principio general de que el nombramiento y cese del Gobierno van unidos al nombramiento y cese de su Presidente. Sin embargo, esta posición de primacía del Presidente del Gobierno no impide que éste deba ser considerado como un órgano constitucional, primario, autónomo y complejo.

La noción del Gobierno ha tratado de ser delimitada desde un doble punto de vista. Por un lado, desde un punto de vista orgánico, tratando de determinar su posición dentro del Poder Ejecutivo, a través de su diferenciación de otros órganos constitucionales y, de forma especial, de la Administración Publica. La polémica en torno a la distinción entre Gobierno y Consejo de Ministros se situaría en esta órbita. Y de otro, a nuestro modo de ver más importante, desde un punto de vista funcional, tratando de deslindar lo que ha de entenderse por función de gobierno.

En el Título IV de nuestra Constitución (Del Gobierno y de la Administración) se recogen los principios y criterios básicos 
del régimen jurídico del Gobierno, siguiendo los postulados del constitucionalismo moderno. El Título se inicia con el artículo 97, del que se deduce dos tipos de funciones: no;

- unas de carácter político, la denominada función de gobier-

- otras de carácter jurídico, que integran la función ejecutiva.

Sin embargo, el estudio de las funciones del Gobierno plantea una problemática importante que deriva de la dificultad que existe para precisar lo que debe entenderse por función de Gobierno. En principio, como indica el propio artículo 97 de la Constitución, la función de gobierno comprendería la política interior y exterior, la dirección de la Administración civil y militar y la defensa del Estado, equiparándose a la denominada función política y sus actos se consideran actos políticos, sometidos únicamente a control político; la otra función, ejecutiva y reglamentaria, se asimila a las funciones administrativas y los actos en que se concretan están sometidos al control jurisdiccional en vía contenciosa $y$, en su caso, constitucional.

No obstante, la doctrina no es unánime a la hora de delimitar la denominada función de Gobierno. Si para SÁNCHEZ AgESTA es aquella «función política cuyas decisiones, sujetas únicamente a los fundamentos mismos del orden constitucional, tienen la característica libertad de la acción política», identificando, por tanto, el acto discrecional con el acto político (al igual que otros autores, como Guaita, Martín Mateo, Gallego Anabitarte - Mozo SeoAne), otro sector doctrinal (López Guerra, Carro FERNÁNDEZ-VALMAYOR y GARCÍA LLOVET) afirma que no hay acto político si hay afección de derechos y libertades fundamentales, por lo que se debe eliminar dicha categoría como mecanismos de exención de control jurisdiccional.

Por tanto, la teoría jurídica clásica se ha mostrado insuficiente para delimitar lo que debe entenderse por "acción de Gobierno» ante el elevado número de variables y elementos no formales que convergen en su concepción, directamente relacionado, además, con la clásica distinción entre actos políticos y actos administrativos y a la dificilmente sostenible tesis de que todos los actos políticos del Gobierno están exentos de control judicial y sometidos únicamente al control político del Parlamento.

Sin entrar en la polémica doctrinal existente en torno a la teoría del acto político, sobre la cual se pronuncia, aunque sólo en parte, el actual artículo 26 de la Ley del Gobierno, y que deberá tener su traducción normativa en el actual proyecto de la Ley de la Jurisdicción Contencioso-administrativa, hay 
que recordar que, recientemente, nuestro Tribunal Supremo ha indicado, siguiendo una tradición jurisprudencial muy conocida, que existen actos de dirección política como categorías de interpretación restrictiva, en principio inmunes al control jurisdiccional pero controlables cuando el legislador haya definido mediante conceptos judicialmente asequibles los límites o requisitos previos a los que deben sujetarse dichos actos de dirección política ${ }^{1}$.

Es por ello que el «acto político» del Gobierno exento del control jurisdiccional como categoría puede ser admitido sólo en determinados ámbitos: en las relaciones entre órganos constitucionales y siempre que no sean afectados derechos fundamentales o intereses legítimos, incluido el interés a la legalidad ${ }^{2}$.

Por otra parte, en el artículo 98.4 de la Constitución se señala que la ley regulará el Estatuto e incompatibilidades de los miembros del Gobierno. La Ley 12/1995, de 11 de mayo, de incompatibilidades de los miembros del Gobierno de la Nación y de los Altos Cargos de la Administración General del Estado, ha dado cumplimiento, en parte, a esta remisión legislativa en materia de incompatibilidades, y así lo reconoce el artículo 14 de la actual Ley del Gobierno, pero quedaba pendiente la aprobación de una ley del Gobierno, en la que se contemplara su organización, competencia y funcionamiento.

La actual Ley del Gobierno responde a ese mandato constitucional dirigido al legislativo para que se proceda al correspondiente desarrollo normativo de este órgano constitucional, deslindado de la Administración, sobre todo tras la aprobación de la Ley 6/1997, de 14 de abril, de Organización y Funcionamiento de la Administración General del Estado (LOFAGE). De este modo, la Ley 50/1997, de 27 de noviembre, concebida como

1 Las recientes sentencias del TS, de 4 de abril de 1997 ("caso Oñederra), Sala Tercera, Pleno, Ponente Trillo Torres; “caso Lucia Urigoitia», Ponente Cáncer Lalanne y «caso Lasa y Zabalas, Ponente Lescure Martín), aunque no son idénticas, tienen el mismo desarrollo argumental sobre los actos de Gobierno, indicándose en el fundamento de derecho séptimo de la primera de las sentencias citadas:

«Reconocido, sin embargo, que nuestro sistema normativo admite la existencia objetiva de unos actos de dirección política del Gobierno en principio inmunes al control jurisdiccional de legalidad, aunque no a otros controles, como son los derivados de la responsabilidad política o del tratamiento judicial de las indemnizaciones que puedan originar, esto no excluye que la vigencia de los artículos 9 y 24.2 de la Constitución nos obligue a asumir aquel control cuando el legislador haya definido mediante conceptos judicialmente asequibles los limites o requisitos previos a los que debemos aceptar el examen de las eventuales extralimitaciones o incumplimiento de los requisitos previos en que el Gobierno hubiera podido incurrir al tomar la decisión".

2 JORDANo FrAGA, Jesús: «Jaque mate al acto politico?», en Revista española de Denecbo Administrativo, núm. 95 (pág. 417 y ss.), Madrid, 1997. 
una ley de "mínimos», regula la composición, organización y funciones del Gobierno, la posición de los órganos de colaboración y apoyo del mismo, el estatuto jurídico de los miembros del Gobierno, las normas relativas al funcionamiento y delegación de competencias, la iniciativa legislativa, la potestad reglamentaria y el control de los actos del Gobierno. Entre las novedades a destacar de esta nueva norma se encuentra la regulación del Gobierno en funciones (Título IV de la Ley, compuesto de un único artículo, el art. 21), que pasamos a analizar.

El Gobiemo en funciones aparece vinculado al cumplimiento del principio y deber de lealtad constitucional, pues su existencia responde a la necesidad de conseguir un normal desarrollo del proceso de formación del nuevo Gobierno, tras una situación de cese del Gobierno hasta entonces en el poder. Como el Gobierno es un órgano colegiado que en su funcionamiento trata de compaginar los principios de estabilidad, permanencia y responsabilidad, la Constitución prevé la existencia de un Gobierno en funciones hasta la toma de posesión del nuevo Gobierno.

En efecto, en nuestra Norma Fundamental, la única referencia a esta figura se encuentra en el artículo 101, específicamente en su segundo apartado. En el apartado $10^{\circ}$ de este artículo se hace una enumeración de carácter taxativo de las causas de cese del Gobierno, y es en el apartado $20^{\circ}$ en el que se indica expresamente que «el Gobierno cesante continuará en funciones hasta la toma de posesión del nuevo Gobierno».

$\mathrm{La}$ Constitución utiliza el término "Gobierno cesante» y no "Gobierno dimisionario», status perfilado por la doctrina y la práctica italiana ${ }^{3}$. La razón es que esta figura institucional responde a otros criterios: el Gobierno dimisionario todavia no ha cesado, sino que se encuentra en una situación intermedia, tras la presentación de la dimisión y en espera de su aceptación por el Jefe del Estado, sin que ello signifique irremediablemente su cese, pues el Gobierno dimisionario puede ser restituido mediante la no aceptación de la dimisión.

En el caso español, frente a esta práctica italiana, el Jefe del Estado, es decir, el Rey, carece de la competencia para oponerse a esa dimisión. Por otra parte, la concepción del Rey en nuestra Constitución, como órgano moderador con limitaciones muy acusadas, veda cualquier interferencia suya en este proceso, de tal forma que cuando se formula una dimisión no tendrá más

${ }^{3}$ Romano, A.: La Fomazione del Govemo, Padova, 1977.

Mazzonı, M. L.: «Note sul Governo privo di fiducias (Rivista Trimestrale de Diritto Pubblico), 1980. 
remedio que aceptar ésta. Por ello, esta distinción efectuada por la doctrina italiana no tiene especial incidencia en nuestro sistema político.

La habilitación del artículo $\mathbf{1 0 1 . 2}$ de la Constitución, tras la quiebra de la relación de confianza en todos y cada uno de los supuestos generadores del cese del Gobierno, se explica, en sus líneas generales (que posteriormente se matizarán) a través de la construcción técnica de la prorrogatio, de forma coincidente con la que se ofrece en la mayor parte de las ocasiones para explicar la posición de transitoriedad de diferentes órganos estatales ${ }^{4}$.

La prorrogatio fue definida por TOSATO durante la elaboración del actual texto constitucional italiano como un instituto cuya aplicación comporta que un órgano ya cesado pueda continuar ejerciendo, aunque de manera limitada, sus atribuciones, y ello no en virtud de un acto especial que conceda la prórroga, sino de derecho» ${ }^{5}$.

El instituto de la prorrogatio se caracteriza, de un lado, por el cese en la titularidad del órgano como presupuesto para su aplicación $y$, de otro, por la existencia de una habilitación temporal y automática para continuar desempeñando las funciones que corresponden a dicho órgano.

No obstante, en la Constitución española resulta dificil encontrar cualquier semejanza en la organización de la continuidad funcional de las Cortes Generales y las del Gobierno. Mientras este último se encuentra tras el cese con un genérico e impreciso deber de continuar desempeñando sus funciones, las Diputaciones permanentes de las Cámaras tienen una esfera sumamente limitada de atribuciones y reducida además a unos supuestos de hecho en los que, en mayor o menor medida, interviene la necesidad, como ha indicado certeramente REvEnga SÁnCHEZ ${ }^{6}$.

4 Las técnicas que aseguran la continuidad no son exclusivas del Derecho Constitucional, pues se utilizan también en otras ramas del Derecho público y privado. Cit. en Romano, A.: La prongatio negli organi costituzionali, Milán, 1967 (págs. 81 y ss.), y en EldA, L.: «Amministrazione ordinaria degli organi costituzionalì, en Enciclopedia del Diritto, t. II, Milán, 1958 (págs. 220 y ss).

Por otra parte, si dejamos a un lado a la Corona, que tradicionalmente ha gozado de la llamada prerrogativa de perpetuidad, en el sistema constitucional español se contemplan otras fórmulas para que el traspaso de la titularidad no ponga en peligro la continuidad de la función: por un lado, la renovación fragmentada o por partes de los titulares que componen el Tribunal Constitucional (art. 159.3 de la Constitución) y, por otro, el mantenimiento provisional, una vez producido el cese, de la titularidad de la función, hasta el momento en que se verifica la sustitución del titular, como ocurre con la renovación del Consejo General del Poder Judicial (art. 115.2 de la Ley Orgánica 6/1985, del Poder Judicial), del Gobierno y con las Cámaras Parlamentarias.

5 Cit. en D'Orazio, Giustino: «Considerazione critiche sulla prorrogatio nella organizacione costituzionale italiana», en Rivista Trimestrale de Diritto Pubblico, 3, 1980.

${ }^{6}$ Revenga Sánchez, Miguel: «El Gobierno en funciones», en Gobierno y Administración en 
En la mayoría de los regímenes parlamentarios, tras la disolución, pese a regulaciones más o menos generosas respecto a la continuidad de la función parlamentaria, lo cierto es que la actividad de las Cámaras se reduce al mínimo, circunscribiéndose por lo general a asuntos de administración interna y a intervenciones en supuestos extraordinarios y urgentes.

Siguiendo la opinión de AgUIAR DE LUQue ?, la noción de Gobierno en funciones tiene contornos propios y la posición de dicho órgano no se explica tan sólo a través de la institución de la prorrogatio. Dos son los elementos generales que matizan, según este autor, dicha noción:

a) La noción de Gobierno cesante no remite tan sólo a la idea de Gobierno en trance de cesar y, por tanto, prorrogado, sino que su posición ha de explicarse en un contexto más amplio, cual es el de la relación fiduciaria, de confianza entre Gobierno y Parlamento. El Gobierno en funciones es un Gobierno cuya posición viene básicamente definida por carecer de la confianza parlamentaria al haberse quebrado la relación fiduciaria. Ello ha permitido en algunos ordenamientos equiparar dicha posición a la del Gobierno recién nombrado que aún no ha obtenido el respaldo de la confianza parlamentaria.

b) La heterogeneidad y ambigüedad de las funciones encomendadas al órgano gubernamental en el régimen parlamentario $y$, paralelamente, la reducción de los mecanismos de control sobre aquél una vez rota la relación de confianza, es lo que ha generado una corriente de desconfianza hacia los Gobiernos en funciones.

Se debe, por tanto, dar cumplimiento a la necesidad de combinar la continuidad del sistema con la limitación del ámbito de competencias de los Gobiernos cesantes. El mayor problema teórico y práctico que tradicionalmente ha planteado dicho período de transición son los límites que enmarcan las facultades del Gobierno cesante y, consecuentemente, los controles a que está sometido.

Como ha señalado WALINE $^{8}$, las circunstancias de la vida social imponen que el Estado no puede quedarse sin dirección, lo que comporta que, a título de excepción, el Gobierno cesante siga ostentando algunas funciones, pero, como toda excepción,

la Constitución (X Jornadas de estudio de la Dirección General del Servicio Juridico del Estado), Madrid, Instituto de Estudios Fiscales, 1988.

7 Aguiar DE LUQUe, Luis: «Estudios sobre el Gobierno», Seminario sobre el proyecto de Ley reguladora del Cobiemo, Madrid, 1996.

${ }^{8}$ WaLINE, M.: «Notes de jurisprudencen (Revue du droit public et de la science politique en France et à l'étranger), 1952, vol. LVIII (págs. 1029 y ss.). 
debe ser «limitada». En todo caso, la actuación del Gobierno en funciones no puede condicionar la del Gobierno entrante, pues lo contrario equivaldría a un evidente fraude constitucional, ya que el saliente no cuenta con la confianza expresa del Congreso de los Diputados, requisito esencial en el funcionamiento de nuestro régimen parlamentario.

\section{ANÁLISIS DE DERECHO COMPARADO}

En relación a la institución gubernamental se ha producido históricamente un movimiento pendular en sus vías de nombramiento y legitimación: pasa de ser designado libremente por el monarca, a mecanismos más o menos explícitos de participación del Parlamento.

De este modo, en el constitucionalismo liberal clásico (como sucede, a modo de ejemplo, en las leyes constitucionales de la III República francesa, en la Constitución suiza de 1874 , y en las leyes constitucionales de la monarquía sueca, como la que modifica la Ley del Parlamento de 1866, etc.), el Gobierno aparece como un comisionado del Parlamento, como «un agente colocado bajo la autoridad y control de los órganos de representacións? ?

Sin embargo, desde principios de este siglo, el Gobierno va a ir cobrando una paulatina autonomía en la práctica constitucional, agudizada tras la primera guerra mundial, que hace necesaria la intervención masiva del Estado en la producción y distribución de bienes y servicios. Las transformaciones del Estado contemporáneo han afectado al tratamiento constitucional del proceso de nombramiento del Gobierno, que se ve nuevamente alterado ante las nuevas funciones de dirección e impulsión del sistema político que se le confieren. La regulación de los textos constitucionales es muy diversa, aunque es posible hacer la siguiente distinción:

a) Designación popular de la cabeza visible del ejecutivo, calificada por algunos como «democracia directa» y que responde al modelo del régimen presidencial.

b) Designación del Gobierno con mediación tácita (cuando la designación se lleva a cabo por otro órgano, que ha de contar con la correlación de fuerzas parlamentarias ante el riesgo de una posible moción de censura) o expresa (a través de una votación

${ }^{9}$ Dugurt, L.: Traité de Droit constitutionnel (vol. II), París, 1928. 
de investidura) del órgano parlamentario, la denominada «democracia mediatizada».

En términos generales, el Gobierno aparece en los textos constitucionales como un órgano colegiado, jurídicamente homogéneo y titular de unas funciones parcamente definidas. En general, la mayoría de los textos constitucionales definen o identifican al Gobierno con el Consejo de Ministros, es decir, con el órgano colegiado supremo del Poder Ejecutivo, formado por el Primer Ministro o Presidente del Consejo y los Ministros.

Por otra parte, son escasos los Estados europeos que por vía constitucional, o más bien por vía legislativa o simplemente reglamentaria, regulan la composición, estructura y funcionamiento del Gobierno, y aun así no todos estos ordenamientos nacionales se ocupan realmente del Gobierno como tal órgano colegiado, sino de organizar los Departamentos ministeriales como tales unidades administrativas. En cuanto a la posición constitucional del Gobierno en funciones, se viene a sostener, con la independencia o no de una regulación constitucional expresa, que sus funciones deben limitarse a la gestión de los asuntos ordinarios y de carácter urgente. Es significativo que ninguna de las grandes democracias clásicas (Reino Unido, Bélgica, Holanda, Luxemburgo, Suecia y Dinamarca) han creido necesario someter a ordenación positiva esta materia.

En relación al Reino Unido, existe una práctica política aceptada, según la cual en el intervalo entre la retirada de un ministro y el nombramiento del sucesor no se discute una cuestión política importante en una u otra Cámara del Parlamento.

En Francia, en base a la jurisprudencia sentada por el Consejo de Estado, el Gobierno no dispone de la totalidad de las competencias, sino sólo de las necesarias para asegurar la expedición de los asuntos corrientes. Así, en el arrêt del Consejo de Estado de 19 de octubre de 1962, en relación a los decretos del Gobierno dimisionario de Pompidou, se afirma que «según un principio tradicional de Derecho público», el Gobierno dimisionario mantiene la competencia para proceder «a l'expedition des affaires n'impliquant pas de choix politiques essentiels", los llamados «affaires courantes».

La Ley Fundamental de Bonn de 1949 establece en su artículo 69, apartado 2, que «el mandato del Canciller Federal o de cualquier Ministro federal caducará en cualquier caso al reunirse una nueva Dieta federal, y el de los Ministros federales expirará también al finalizar por cualquier otro motivo el del propio Cancillens. En el apartado 3 del mismo artículo se indica 
que «a requerimiento del Presidente Federal, estará obligado el Canciller federal, y todo Ministro lo estará asimismo a requerimiento del propio Presidente o del Canciller, a seguir despachando los asuntos hasta el nombramiento del suceson. En relación a este artículo se pueden hacer dos observaciones:

1. $\left.{ }^{2}\right)$ No opera el principio institucional de la prorrogatio o, al menos, éste no de forma automática, pues es necesario el previo requerimiento, de ahí el carácter potestativo de que goza el Presidente Federal, en quien reside la competencia de prescindir o de instar al Canciller a que continúe en su puesto.

2.) La prórroga de funciones, si se lleva a efecto, tiene carácter individualizado, a no ser que se haga extensiva al Gobierno en su conjunto.

En Italia, la Constitución de 1947 diferencia el Gobierno recién constituido que debe presentarse ante el Parlamento para obtener la confianza de éste, del Gobierno dimisionario a la espera de la aceptación de la dimisión presentada por el Jefe del Estado, ya que no cuenta con la confianza de las Cámaras. En todo caso, la doctrina italiana ${ }^{10}$ mantiene la aplicación de dos criterios generales que limitan las competencias del Gobierno prorrogado:

- en primer lugar, cuando surjan dudas sobre si una determinada decisión se mantiene en el ámbito de la conservación y tutela de los intereses generales, o si, por el contrario, se encuadra dentro de una política discrecional de ordenación del futuro, el Gobierno cesante debe de abstenerse de actuar;

- en segundo lugar, si por razones de urgencia el Gobierno cesante se entiende legitimado para actuar, en los casos dudosos anteriormente mencionados o incluso en otros en que la decisión implique una valoración todavía más marcadamente política, su actuación debe prejuzgar lo menos posible la futura actuación del nuevo Gobierno.

La Constitución de la República Portuguesa es uno de los textos más explícitos en relación con la posición constitucional del Gobierno. En su artículo 189.4 se indica expresamente: «En caso de dimisión del Gobierno, el Primer Ministro del Gobierno cesante quedará separado del cargo en la fecha de nombramiento y toma de posesión del nuevo Primer Ministro", y en el apartado 5, de este mismo artículo, que «antes de que sea examinado su programa por la Asamblea de la República, o

10 Galizia, M.: Studi sui rapporti fra Parlamento e Govemo, Milán, 1972. 
después de su dimisión, el Gobierno se limitará a realizar los actos estrictamente necesarios para asegurar la gestión de los negocios públicos».

\section{REGULACIÓN DEL GOBIERNO EN FUNCIONES}

La regulación del Gobierno en funciones experimentó diversos cambios en nuestro proceso constituyente. Así, en el Anteproyecto constitucional se preveía la continuación en funciones del Gobierno cuando el cese se debiera a la celebración de elecciones generales y únicamente la continuidad de los ministros, excepcionando al Presidente del Gobierno, en el caso de que el cese se produjera por dimisión o pérdida de la cuestión de confianza, ya que la finalidad última de esta prórroga de funciones era, en puridad, preservar la continuidad de la función de dirección de la Administración, y tal necesidad se veía satisfecha con el mantenimiento de los ministros y demás órganos superiores de los Departamentos ministeriales ${ }^{11}$.

Finalmente, en el artículo 101 de la Constitución se prevé la posibilidad de que el Gobierno, en su totalidad, continúe en funciones tras el cese por las causas fijadas en su apartado primero. La enumeración del primer párrafo tiene carácter taxativo, como quedó de manifiesto tras la supresión por parte de la Comisión Mixta Senado-Congreso de la incapacidad del Presidente como supuesto de cese del Gobierno, con el propósito de no admitir otras causas de cese que las mencionadas expresamente. $\mathrm{Al}$ no estar previsto, por tanto, en el texto constitucional este supuesto, puede entenderse que en este caso se hace cargo de la Presidencia del Gobierno el Vicepresidente y que éste puede continuar dirigiendo el Gobierno por tiempo indefinido, hasta que cese la incapacidad.

Todos los supuestos previstos de cese tienen algo en común, pues, de un modo u otro, todos ellos implican una ruptura o

${ }^{11}$ En un principio, el entonces artículo 98 contenía tres apartados, tal como recoge el Anteproyecto de la Ponencia (BOC 5 de enero de 1978):

1. El Gobiemo cesa tras la celebracion de elecciones generales, en caso de pérdida de la confianza parlamentaria, o por dimisión de su Presidente.

2. En el primer supuesto, el Gobiemo continia en funciones basta la toma de posesión del nuevo Cobierno.

3. En caso de pérdida de confianza parlanentaria o de dimision del Presidente, los demás miembros del Gobiemo continuarán en funciones basta que tome posesión un nuevo Gobierno.

El Informe de la Ponencia refundió, en base a una enmienda del Grupo Socialista del Congreso, los dos últimos en uno solo, ya que ambos se referían al mismo supuesto de continuidad del Gobierno en funciones, indicándose que no habia ninguna razón para establecer la distinción que señalaba el anteproyecto. 
extinción de la relación fiduciaria Gobierno-Congreso de los Diputados, que en el Ordenamiento español se materializa siempre a través de la figura del Presidente del Gobierno.

No obstante, la práctica española ha sido un tanto irregular desde sus inicios. Así, por ejemplo, en 1979 no hubo Real Decreto que formalizara la crisis y en 1981 y 1982 los Reales Decretos no mencionaban la fecha de dimisión ni su aceptación por el Rey.

Aun así, el orden secuencial de acontecimientos previsto por el constituyente es el siguiente: producida alguna de las circunstancias determinantes del cese del Gobierno, el Presidente eleva al Rey el Decreto de cese a la vez que lo refrenda (con ocasión de la dimisión de Adolfo Suárez como presidente del Gobierno, el Decreto de cese fue refrendado por el Ministro de Justicia), permaneciendo en funciones durante el período que media entre la publicación del Decreto y la toma de posesión del nuevo Gobierno que representa la fecha a término del Gobierno en funciones:

\section{TRAS LA CELEBRACiÓN DE ELECCIONES GENERALES}

Este supuesto de cese del Gobierno es distinto de la convocatoria de elecciones generales que, como tal, no es un supuesto de cese de aquél. No obstante, pensamos que el acto formal de convocatoria de elecciones generales, que significa que el gobierno entiende que no goza de la confianza parlamentaria y pretende, por lo tanto, una renovación de la misma, debe suponer un cambio en la posición constitucional de aquel, no pudiendo actuar con plenitud de competencias, aunque, jurídicamente hablando, no estemos en presencia de un gobierno en funciones. Sin embargo, la actual Ley del Gobierno, quizás siguiendo demasiado literalmente los supuestos de cese establecidos en el artículo 101 de nuestra Constitución, no contempla este supuesto.

La mayoría de la doctrina indica que el comienzo del cese se inicia al día siguiente de la celebración de las elecciones y no en el día de la proclamación oficial, por la Junta Central Electoral, de los resultados de las mismas. Estas elecciones son las que se refieren al Congreso de los Diputados y no las que puedan afectar al Senado. Sin embargo, para Revenga SÁnCHEZ ${ }^{12}$, el cese se produce automáticamente el mismo día en que se celebran las

12 Revenga SANChez, Miguel: op. cit. 
elecciones generales y con total independencia del resultado de las mismas.

Por lo que se refiere a este supuesto, la práctica seguida ha sido heterogénea:

- En las elecciones que tuvieron lugar tras la aprobación de la Constitución (1-3-1979), el criterio seguido se puede calificar de sorprendente, pues ni medió dimisión, ni cese del Gobierno, desarrollándose todo el proceso de investidura y nombramiento sin cesar el Gobierno anterior, por lo que formalmente no hubo Gobierno cesante. Sin embargo, se entiende que éste operó como tal desde el 2 de marzo (día siguiente a la celebración de las elecciones) al 6 de abril (toma de posesión del nuevo Gobierno).

- En las segundas elecciones (28-10-1982), el Real Decreto de cese del Gobierno es publicado varios días después de la celebración de las elecciones y de la constitución de las nuevas Cámaras, coincidiendo con el nombramiento y toma de posesión del nuevo Gobierno (1-12-1982). Tampoco en este caso hubo formalmente Gobierno en funciones.

- En las elecciones celebradas en 1986 (21-6-1986), se publicó al día siguiente un Decreto de cese haciendo mención explícita al artículo 101 de la Constitución.

\section{PÉRDIDA DE LA CONFIANZA PARLAMENTARIA}

En los casos de pérdida de la confianza parlamentaria, tras la dimisión obligatoria por la pérdida de la cuestión de confianza (art. 112 CE), el Presidente del Gobierno presenta la dimisión al Rey y éste declara su cese inmediatamente. Tras la dimisión obligatoria por el triunfo de una moción de censura (art. $113 \mathrm{CE}$ ), el Rey simultáneamente en sendos Reales Decretos declara el cese del Presidente del Gobierno, el cese de los demás miembros del Gobierno y el nombramiento del nuevo Presidente propuesto en la moción de censura. A este respecto, hay que señalar la ausencia de cualquier practica política, pues los únicos supuestos en que se ha producido la puesta en práctica de ambas instituciones, tanto la cuestión de confianza como la moción de censura, nunca han llegado a producir la pérdida de la confianza parlamentaria en el Gobierno.

\section{DimISión VOlUNTARIA DEL PRESIDENTE DEL GOBIERNO}

En el supuesto de dimisión voluntaria del Presidente del Gobiemo, y aunque en opinión de SÁNCHEZ AGESTA, este 
supuesto no tiene fórmula jurídica prevista en la Constitución y puede operar tanto un Decreto con el refrendo del propio Presidente dimisionario o una comunicación de éste o del Rey a las Cortes, la mayoría de la doctrina ha indicado que la dimisión actúa como causa de cese sólo a partir del momento en que es aceptada por el Rey y publicada en el BOE, a través del correspondiente Real Decreto. Igualmente el Rey debe declarar el cese de los demás miembros del Gobierno, para pasar al nombramiento del nuevo según el procedimiento del artículo 99.

Este supuesto de cese del Gobierno a causa de la dimisión voluntaria del Presidente del Gobierno, también ha tenido lugar y con criterios no plenamente adecuados a la dicción de la Constitución. Fue con ocasión de la dimisión de Adolfo Suárez, cuya única constancia documental se halla en la comunicación de la Presidencia del Congreso inserta en la serie I del Boletín Oficial de las Cortes Generales-Congreso de los Diputados. La dimisión se produjo el 28 de enero de 1981 en el curso de una audiencia que le fue concedida por el Rey.

El Consejo de Ministros fue convocado para el día siguiente, $y$, al término de la reunión, la Secretaria de Estado para la Información hacía público un comunicado por el que se daba a conocer la dimisión, aludiendo en el mismo a que «queda abierta la vía constitucional señalada en los artículos 101 y 99 de la Constitucióny. El mismo día 29 el Presidente se dirige a la nación por medio de un mensaje radiotelevisado, y al día siguiente, el Rey, tras una audiencia con el Presidente del Congreso, comienza una primera ronda de consultas con vistas a la designación de candidato.

Todo este proceso no encuentra eco en las páginas del Boletín Oficial del Estado hasta casi un mes más tarde (26 de febrero), en los que aparecen los Reales Decretos 249 y 250/1981, ambos de 25 de febrero, por los que use formaliza el fin de las funciones como Presidente del Gobierno" de Adolfo Suárez y se nombra Presidente a Calvo Sotelo. El texto del Real Decreto de cese no alude a la aceptación de la dimisión por el Rey, sino que escuetamente señala que «como consecuencia de la dimisión de don Adolfo Suárez González, vengo a declarar el fin de sus funciones (...)»).

$\mathrm{Y}$ es que, de confirmarse la práctica que se produjo con la dimisión de Adolfo Suárez en 1981, la plasmación jurídica del cese no se produce hasta que no concluye el procedimiento de formación del nuevo Gobierno. De ahí que, en rigor, como ha señalado SATRÚSTEGUI ${ }^{13}$, el Gobierno cesante sólo operó, formal-

13 Satrústegu, Miguel: «El cese del Gobierno y el Gobierno cesante», en Comentarios a las leyes polititas, Madrid, 1985 (vol. VIII). 
mente, en las breves horas que mediaron entre la publicación del cese y la toma de posesión de Leopoldo Calvo Sotelo, ese mismo dia, como nuevo Presidente del Gobierno.

Hay que hacer especial mención a la cuestión de la práctica del control parlamentario sobre la actuación del Gobierno en funciones en este supuesto. En el Senado, una vez conocida la dimisión de Suárez, la Mesa acordó eliminar del orden del día del Pleno los ruegos, preguntas, debates sobre declaraciones del Gobierno e interpelaciones (en definitiva, la totalidad de los actos de control político). El Presidente del Senado, al inicio del Pleno inmediato posterior a la dimisión, indicó:

«Como consecuencia de que a tenor del artículo 101 de la Constitución la actual situación del Gobierno (...) es la de Gobierno en funciones hasta que sea nombrado el nuevo Gobierno, ha entendido la Mesa (...), de conformidad con los señores portavoces, que no hacía autorizable que se debatiesen o se explanasen los restantes actos parlamentarios del orden del día, ruegos y preguntas, debates sobre declaraciones del Gobierno e interpelaciones».

Por su parte, en el Congreso de los Diputados se celebró una sesión de control la víspera del debate de investidura del candidato de UCD, Calvo Sotelo.

\section{Fallecimiento del Presidente DEL GoBierno}

En el caso de fallecimiento del Presidente del Gobierno, el Gobierno en funciones estará presidido por su Vicepresidente, como indicaba el artículo 3 de la recientemente derogada Ley 10/1983, de Organización de la Administración Central del Estado ( $\mathrm{ELl}$ Vicepresidente del Gobierno asumirá las funciones del Presidente en los casos de fallecimiento, ausencia en el extranjero o enfermedad de éste, sin perjuicio de lo dispuesto al respecto en la Constitucióny), y así parece seguir el artículo 13 de la actual Ley del Gobierno, cuando regula los supuestos de suplencia por vacante, ausencia o enfermedad.

Finalmente, en relación al ejercicio de las funciones por estos Gobiernos, hay que dejar constancia que tampoco el análisis casuístico de las ocasiones en que ha operado un Gobierno como cesante parece respaldar restricción juridica alguna.

Así, en los Gobiernos que han operado en condición de cesantes, han ejercido dos facultades que virtualizan de modo especialmente intenso la capacidad de dirección política del 
órgano gubernamental y que, pese a ello, no suscitaron, en principio, problemas jurídicos:

a) Potestad para dictar Decretos-leyes: el Gobierno de Calvo Sotelo dictó un Decreto-ley con fecha de 23 de octubre de 1982 y el Gobierno de Felipe González dictó otro con fecha de 23 de mayo de 1986, y en ambos casos tras la disolución de las Cámaras.

b) Legitimación para promover conflictos de competencias ante el Tribunal Constitucional: en el Gobierno cesante de Calvo Sotelo se promovieron cuatro conflictos positivos de competencias: 420/1982, 430/1982, 446/1982 y 447/1982; en el Gobierno cesante de Felipe González se interpusieron dos conflictos: 812/1986 y 813/1986.

Por todo ello, la aprobación de una Ley del Gobierno en la que se regule el Gobierno en funciones se presenta no sólo como conveniente, sino necesaria, sobre todo, cuando contiene una previsión legal del modo de ejercicio de sus potestades por dicho Gobierno en funciones.

\section{LA LEGISLACIÓN AUTONÓMICA}

La fórmula del Gobierno en funciones ha sido también acogida en los Estatutos de Autonomía de las Comunidades Autónomas. En líneas generales, la mayoría de los Estatutos se inspiran en la regulación contenida en la Constitución española, aunque se pueden diferenciar tres grupos de Estatutos:

a) Aquellos que carecen de regulación de este supuesto: Estatutos de la Comunidad Valenciana, de Cataluña y de Castilla y León.

b) Estatutos que contienen una regulación similar a la del artículo 101 de la Constitución: Estatutos de Galicia, Andalucía, Asturias, Cantabria, La Rioja, Murcia, Aragón, Castilla-La Mancha, Extremadura, Islas Baleares, Madrid, País Vasco y la Ley Orgánica de reintegración y amejoramiento del régimen foral de Navarra.

c) Estatutos que contienen algunos elementos diferenciadores: Estatuto de Canarias (el art. 19.2 establece un limite temporal de quince días, a contar desde la fecha de nombramiento del Presidente).

El artículo 59 de la Ley 3/1982, de 23 de marzo, del Parlamento, del Presidente y del Consejo Ejecutivo de la 
Generalidad catalana, establece que el Presidente de la Generalidad cesa por:

a) Renovación del Parlamento a consecuencia de unas elecciones generales.

b) Aprobación de una moción de censura.

c) Denegación de una cuestión de confianza.

d) Dimisión.

e) Por notaria incapacidad permanente, física o mental, reconocida por el Parlamento, que le inhabilite para el ejercicio del cargo.

En los cuatro primeros casos a que se refiere el apartado anterior, el Presidente de la Generalidad deberá continuar en el ejercicio del cargo hasta que su sucesor haya tomado posesión. En el último caso, así como en el de muerte, el Presidente será sustituido interinamente en sus funciones por el Presidente del Parlamento, que convocará a la Cámara para la elección del nuevo Presidente de la Generalidad dentro de los ocho días siguientes. El Presidente del Parlamento será sustituido en sus funciones por el Vicepresidente Primero.

El artículo 31.2 del Estatuto de Autonomía del País Vasco se limita a indicar que «el Gobierno cesante continuará en funciones hasta la toma de posesión del nuevo Gobierno". $\mathrm{Ha}$ sido mediante un posterior desarrollo normativo cuando en esta Comunidad Autónoma se ha intentado limitar la actuación del Gobierno en funciones. Así, la Ley 7/1981, de 30 de junio, de Regulación del Gobierno y su Presidente, diferencia dos fórmulas sustitutorias: el Lehendakari interino y el Lehendakari en funciones, en función de una incapacidad o imposibilidad relativa o absoluta.

El primer supuesto entra en juego cuando se dan las condiciones recogidas en el artículo 9.1, es decir, imposibilidad transitoria o temporal del Lehendakari, apreciada por el Gobierno a instancia propia o del Presidente del Gobierno; el segundo supuesto se produce cuando se cumplen los requisitos del artículo 13.1, además de transcurrido el plazo de cuatro meses ininterrumpidos sin que hubieran desaparecido las causas a las que se refiere el artículo 9, después de la celebración de las elecciones generales al Parlamento, en los casos de pérdida de confianza parlamentaria, por dimisión y por fallecimiento.

En todo caso, el artículo 13.3 establece que el Lehendakari cesante y su Gobierno continuarán en el ejercicio de sus funciones a fin de garantizar «el buen funcionamiento de la Administración y el adecuado traspaso de poderes hasta la toma de 
posesión del nuevo Lehendakaris, salvo cuando el cese se produjera por fallecimiento o incapacidad del Lehendakari, en cuyo caso se producirá la sustitución. Es decir, se mantiene la integridad del equipo gubernamental, asumiendo la prorrogación del Gobierno y de su Presidente, aunque circunscrito a garantizar expresamente «el buen funcionamiento de la Administración». Y es que, a pesar de la indeterminación y ambigüedad de la citada expresión, ésta se convierte en el límite establecido por la ley para excluir la realización de otro tipo de actos, los actos políticos o de dirección política ${ }^{14}$.

La Ley 3/1995, de 8 de marzo, de Régimen jurídico del Gobierno y la Administración Pública de la Comunidad Autónoma de La Rioja, regula en distintos preceptos los supuestos de cese del Presidente de la Comunidad y del Consejo de Gobierno, aunque ambos están directamente relacionados. El artículo 12 prevé el supuesto de cese del Presidente de la Comunidad Autónoma por los siguientes motivos:
a) Dimisión.
b) Fallecimiento.
c) Incapacidad que le inhabilite para el ejercicio del cargo.
d) Disolución de la Diputación General de La Rioja.
e) Pérdida de la condición de Diputado.
f) Pérdida de la cuestión de confianza.
g) Aprobación de la moción de censura.

En los supuestos de dimisión, disolución de la Diputación General o pérdida de la cuestión de confianza, el Presidente cesante continuará en el ejercicio de sus funciones hasta la toma de posesión del nuevo Presidente. En el supuesto de aprobación de moción de censura, el Presidente de la Diputación General lo comunicará al Rey, a efectos del nombramiento del candidato propuesto como Presidente de la Comunidad Autónoma. Hasta la toma de posesión del nuevo Presidente continuará en funciones el Presidente cesante.

${ }^{14}$ Como ejemplo de desconocimiento de los limites de un Gobierno dimisionario, GarciA HerrerA señala el proceso de negociación de las transferencias a la Comunidad Autónoma llevado a cabo por el Vicepresidente Fernández después del cese/dimisión de Garaicoechea. En dicho proceso de negociación, se fijó el contenido de las condiciones aceptadas y el contexto general de los acuerdos. Para el citado autor, cel deseo de demostrar la eficacia de una gestion, el traspaso de una berencia al sucesor, la inserción del proceso de transferencias en un marco polémico de lecturas del Estatuto de Autonomia y de enfrentamiento entre la Administración central y la autonómica permiten, efectivansente, aceptar la calificación politica $y$, por tanto, considerar que el Gobierno en funciones actuó competencias que, por su situación, no le correspondiann.

Cit. en García Herrera, Manuel Ángel: «La continuidad del Gobierno Vascom, Revista vasca de Administración pública, 1983, núm. 11 (págs. 83 y ss.). 
El artículo 13 establece que el Presidente en funciones ejercerá todas las atribuciones del Presidente, salvo las de definir el programa de gobierno y nombrar o cesar Consejeros, sin que pueda ser objeto de moción de censura ni plantear cuestión de confianza. Por su parte, en el artículo 22 de la citada ley se indica que el Consejo de Gobierno cesará cuando lo haga su Presidente. No obstante, aquél continuará en funciones hasta la. toma de posesión del nuevo Consejo.

La Ley 1/1995, de 16 de febrero, de Normas reguladoras del Presidente y del Gobierno de Aragón, que deroga parcialmente la Ley 3/1984, de 22 de junio, de Regulación del Presidente, de la Diputación General y de la Administración de la Comunidad Autónoma de Aragón, establece en su artículo 3 que el Presidente cesa:

a) Después de la celebración de elecciones a Cortes de Aragón.

b) Por aprobación de una moción de censura.

c) Por denegación de una cuestión de confianza.

d) Por dimisión.

e) Por incapacidad física o psíquica que le imposibilite para el ejercicio de su cargo.

f) Por sentencia firme de los tribunales que le imposibilite para el ejercicio del cargo. Aragón.

g) Por pérdida de la condición de Diputado a las Cortes de

h) Por incompatibilidad no subsanada.

En los cuatro primeros supuestos, el Presidente deberá continuar en el ejercicio del cargo hasta que su sucesor haya tomado posesión. En el resto de supuestos y, en el caso de fallecimiento, ejercerá provisionalmente las funciones de Presidente el Consejero a quien corresponda según el orden de prelación de los Departamentos. En estos casos el Presidente de las Cortes abrirá inmediatamente consultas con las fuerzas parlamentarias para presentar un candidato a la Presidencia.

En el artículo 4 se indica que el Presidente en funciones tendrá derecho a los mismos honores y tratamiento que la presente Ley reconoce al Presidente. Igualmente ejercerá las funciones y competencias que esta Ley y el resto del ordenamiento jurídico aplicable otorga al Presidente, aunque no podrá plantear la cuestión de confianza, disolver las Cortes ni ser objeto de una moción de censura.

La Ley Foral 23/1983, de 11 de abril, de Normas reguladoras del Gobierno y de la Administración de la Comu- 
nidad Foral, establece en su artículo 17 que el Gobierno cesará tras la celebración de elecciones para el Parlamento de Navarra, cuando éste le niegue su confianza al Presidente o apruebe una moción de censura, o por dimisión, inhabilitación por sentencia firme o fallecimiento del Presidente, y en su artículo 18 que el Gobierno cesante continuará en funciones hasta la toma de posesión del nuevo Gobierno.

Específicamente, en relación al Presidente del Gobierno, el artículo 30 establece que el Presidente del Gobierno cesará como consecuencia de: lamento.

a) La celebración de elecciones para la renovación del Par-

b) La denegación de una cuestión de confianza.

c) La aprobación de una moción de censura.

d) Dimisión.

e) Sentencia firme que implique su inhabilitación para el cargo.

f) Fallecimiento.

El Presidente cesante continuará en el ejercicio de sus funciones hasta la toma de posesión del nuevo Presidente. No obstante, el Presidente en funciones no podrá, en ningún caso, ser objeto de moción de censura ni plantear la cuestión de confianza.

Mucho más específica es la Ley $2 / 1997$, de 28 de abril, de Régimen Jurídico del Gobierno y de la Diputación Regional de Cantabria, respecto a la regulación que hace del Consejo de Gobierno en funciones, cuyo artículo 26 establece que el Consejo de Gobierno cesará con el cese de su Presidente, pero continuará en sus funciones hasta la toma de posesión del nuevo Consejo. El Consejo de Gobierno cesará tras la publicación del Decreto de convocatoria de elecciones a la Asamblea Regional de Cantabria, cuando ésta apruebe una moción de censura o por dimisión, incapacidad o fallecimiento de su Presidente.

En el artículo 28 se indica que el Consejo de Gobierno cesante continuará actuando en funciones tras la publicación del Decreto de cese, con las limitaciones establecidas en la Constitución, en el Estatuto de Autonomía y en esta Ley, debiendo limitarse a adoptar las decisiones que requiere «el funcionamiento normal de los servicios públicos» y a propiciar el adecuado desarrollo del procedimiento de formación del nuevo Consejo de Gobierno. En ningin caso, el Consejo de Gobierno en funciones puede presentar Proyectos de Ley a la Asamblea Regional de Cantabria, someterse a la cuestión de confianza o 
ser objeto de una moción de censura. Las delegaciones legislativas otorgadas por la Asamblea Regional quedan en suspenso durante todo el tiempo que el Consejo de Gobierno esté en funciones.

\section{LA LEY DEL GOBIERNO: EL ARTÍCULO 21}

Con independencia de las modificaciones que la Ley 50/1997, de 27 de noviembre, del Gobierno ha supuesto en el Derecho hasta ahora vigente, hay que señalar que el nuevo texto legal viene a poner remedio a una situación de dispersión y fragmentación normativa, cuando no de vacío normativo. Se trata en suma de una ley necesaria, que deberá ser objeto del desarrollo reglamentario correspondiente.

No suscribimos, por tanto, aquellas tesis doctrinales que señalan la imposibilidad de regular por ley la figura del gobierno en funciones, por no existir una previsión constitucional expresa en el artículo 101 de nuestra Norma Fundamental y por entender que se trata de una cuestión en la cual la regulación constitucional y la madurez de nuestro propio sistema democrático la hacen innecesaria, siendo suficientes las normas de cortesía constitucional. Antes al contrario, pensamos que la práctica política anteriormente descrita hace necesaria dicha regulación legal, la cual deberá ser complementada, por lo que a los aspectos procedimentales se refiere, por la correspondiente normativa reglamentaria.

Por otra parte, la ley se presenta como ordinaria, ya que la regulación del Gobierno no forma parte de las materias integrantes del núcleo de las reservas a Ley orgánica (enumeradas en el art. 81.1 de la Constitución). Como ya se ha indicado anteriormente, la Constitución (art. 98) hace únicamente una remisión a la Ley. En todo caso, el artículo 86.1 de la Constitución excluye del ámbito del Decreto-ley el «ordenamiento de las instituciones básicas del Estadon, entre las que se encuentra el Gobierno.

\section{PRECEDENTES PARLAMENTARIOS (Legislaturas I, IV Y V)}

Ya en la I Legislatura (1979-1982) se presentó un proyecto de Ley Orgánica del Gobierno, de la Administración del Estado y de la Función Pública por el Gobierno de UCD, en 1980. Sin embargo, este proyecto fue retirado por el propio Gobierno en marzo de 1981. 
No será hasta la IV Legislatura (1989-1993) cuando se presente, de nuevo, un borrador de un anteproyecto de Ley Reguladora del Gobierno de la Nación, en junio de 1991.

Este intento no fructificará, siendo más fecunda la siguiente legislatura, pues en la V Legislatura (1993-1996) se presentarán diversos textos.

Éstos fueron una proposición de Ley del Gobierno y de la Administración del Estado (julio de 1994), presentada por el Grupo Parlamentario Popular; un borrador de anteproyecto de Ley Reguladora del Gobierno de la Nación (presentado en febrero de 1995) y un posterior proyecto de Ley Reguladora del Gobierno (octubre de 1995), por el Gobierno del PSOE. Al disolverse las Cortes por Real Decreto 1/1996, de 8 de enero, el proyecto caducó en su tramitación parlamentaria.

La proposición de Ley del Gobierno y de la Administración del Estado del Grupo Popular no regulaba la figura del Gobierno en funciones, a diferencia del proyecto de Ley Reguladora del Gobierno del PSOE. Sin embargo, dicho proyecto, que debe considerarse como el verdadero antecedente parlamentario de la actual regulación, no iba más allá de establecer algunos límites concretos a las competencias del Gobierno en funciones. Así, debe destacarse cómo en el también artículo 21 del proyecto de Ley Reguladora del Gobierno ${ }^{15}$, si bien no se establecía con claridad cuál era la posición constitucional del Gobierno en funciones, se señalaban, no con excesivo rigor constitucional, aquellas actuaciones que el Gobierno en dicha situación no podía realizar, entre ellas, disolver alguna de las Cámaras legislativas o las Cortes Generales, someter decisión alguna a referéndum consultivo o someterse a la cuestión de confianza.

${ }^{15} \mathrm{El}$ artículo 21 del proyecto de Ley Reguladora del Gobierno ( $B O C G$, Serie A, núm. 141-1), establecía lo siguiente:

1. El Gobierno cesante continúa actuando en funciones tras la publication del Real Decreto de cese, con las limitaciones establecidas en la Constitucion $y$ en esta Ley.

2. El Gobierno en funciones:

A) Debe propiciar el normal desarmollo constitucional del procedimiento de formacion del nuevo Gobierno y ejercer sus competencias conforme al uso constitucional.

B) No puede:

a) Disolver alguna de las Cámaras legislativas o las Cortes Generales.

b) Aprobar el proyecto de Loy de Presupuestos Generales del Estado o someter decisión alguna a referéndum consultivo.

c) Presentar proyectos de Ley al Congreso de los Diputados, en el caso de que el cese del Gobiemo se bubiera debido a la celebración de elecciones generales.

d) Someterse a la cuestion de confianza o ser objeto de zma moción de censura.

3. Las delegaciones legislativas otorgadas por las Cortes Generales quedan en suspenso durante todo el tiempo que el Gobierno esté en funciones, precisando la ratificación por aguéllas cuando la causa del cese del Presidente del Gobiemo bubiera sido la celebración de electiones generales. 
En efecto, en todos estos casos, no era el Gobierno quien debía llevar a cabo esas acciones, pues en el primer caso, es el Rey, según disponen con toda claridad los artículos 62.b), 99 y 115.1 de la Constitución; ni siquiera puede el Gobierno proponer al Rey la disolución de las Cámaras, ya que en el supuesto de la disolución potestativa sólo corresponde tal propuesta al Presidente del Gobierno. Asimismo, respecto al referéndum consultivo previsto en el artículo 92 de la Constitución, no lo puede convocar el Gobierno, sino sólo el Rey, mediante propuesta del Presidente del Gobierno. Igualmente, es el Presidente del Gobierno, previa deliberación del Consejo de Ministros, quien puede plantear la cuestión de confianza (art. 112 de la Constitución).

\section{El ARTí́culo 21 DE LA LEY DEL GobieRNo}

La aprobación de la actual Ley 50/1997, de 27 de noviembre, del Gobierno, que contó con un importante consenso parlamentario, como es lógico en una ley de estas características y significado, presenta, en relación con la figura del Gobierno en funciones, regulado en el Título IV de la Ley, además de la mención expresa que el artículo 16.3 hace en torno a la continuidad de los Directores de los gabinetes, en el supuesto de Gobierno en funciones, hasta la formación del nuevo Gobierno, una serie de diferencias importantes en relación con el anterior proyecto de Ley Reguladora del Gobierno del PSOE:

a) Por un lado se determina, de una forma más contundente y clara, la posición constitucional del Gobierno en funciones, al señalar el artículo 21.3 que «El Gobierno en funciones facilitará el normal desarrollo del proceso de formación del nuevo Gobierno y el traspaso de poderes al mismo y limitará su gestión al despacho ordinario de los asuntos públicos, absteniéndose de adoptar, salvo casos de urgencia debidamente acreditados o por razones de interés general cuya acreditación expresa así lo justifique, cualesquiera otras medidas». La diferencia en relación con el artículo 21.2.a) del proyecto de Ley de 1995 parece evidente.

Con ello, nuestra regulación se incorpora al criterio general del Derecho comparado, y también de nuestra legislación autonómica, de limitar la actuación del Gobierno al despacho ordinario de los asuntos públicos, concepto jurídico indeterminado que tiene su antecedente en los affaires courantes, que ha tomado su base en la doctrina del Consejo de Estado Francés, desde el "arrêt Syndicat Regional des Quotidiens d'Algerie», de 4 de abril 
de 1952 y confirmado en otros posteriores ${ }^{16}$, debiendo, por lo tanto, abstenerse de adoptar decisiones de carácter "político» que puedan comprometer la actuación del futuro gobierno. Y ello, como se señala en la propia Exposición de Motivos de la Ley, «con base en el principio de lealtad constitucional, delimitando su propia posición constitucional y entendiendo que el objetivo último de toda su actuación radica en la consecución de un normal desarrollo del proceso de formación del nuevo Gobierno.»

La regulación del articulo 21.3 supone la normativación de lo que debe ser un uso constitucional adecuado a un Estado democrático que no siempre se ha producido entre nosotros. $Y$ así se entendió en los debates parlamentarios en torno al proyecto de ley, pues la redacción original del Proyecto únicamente fue alterada con motivo de la aceptación de la enmienda núm. 28, presentada por el Grupo Parlamentario Catalán, que suponia la adición de un inciso final al precepto en cuestión, previéndose así las circunstancias de interés general, debidamente acreditadas, que pudieran justificar la adopción de determinadas medidas por parte del Gobierno en funciones.

b) Por otro lado, se establecen límites concretos a las funciones que pueden desempeñar tanto el Presidente del Gobierno en funciones, como el propio Gobierno en funciones, distinción ésta que no figuraba en el Proyecto de Ley de 1995. En efecto, tras enumerar los supuestos de cese del Gobierno, con una redacción exactamente igual a la del artículo 101 de la Constitución, sin introducir ningún otro supuesto, por entender que la regulación constitucional tiene un carácter taxativo, establece una serie de limitaciones a las actuaciones del Presidente del Gobierno y del Gobierno como órgano colegiado.

Así, el Presidente del Gobierno en funciones no puede ejercer las siguientes facultades:

a) Proponer al Rey la disolución de alguna de las Cámaras, o de las Cortes Generales.

16 Ya en la IV República la magistratura censuró la extralimitación del gabinete dimisionario y reclamó un control jurisdiccional de los actos de dicho Gobierno. Con la decisión de 4 de abril de 1952, el Consejo de Estado francés anuló un decreto de 1946, dictado por el Gobierno dimisionario, por considerar que las funciones de este Gobierno se tenian que reducir a la administración ordinaria.

En la V República, la sentencia del Consejo de Estado de 19 de octubre de 1962 reafirmó la invalidez de los actos que excedian de la capacidad del Gobierno, que debia limitarse a la gesción de asuntos corrientes. En esta última sentencia se afirma que «según principio tradicional de Derecho puiblico», el Gobierno dimisionario mantiene la competencia para proceder «ì l'expedition des affaires courantes"y. 
b) Plantear la cuestión de confianza.

c) Proponer al Rey la convocatoria de un referéndum consultivo.

Por su parte, el Gobierno en funciones no podrá ejercer las siguientes facultades:

a) Aprobar el Proyecto de Ley de Presupuestos Generales del Estado.

b) Presentar proyectos de ley al Congreso de los Diputados $o$, en su caso, al Senado.

Asimismo, según dispone el artículo 21.6, «las delegaciones legislativas otorgadas por las Cortes Generales quedarán en suspenso durante todo el tiempo que el Gobierno esté en funciones como consecuencia de la celebración de las elecciones generales».

Esta serie de limitaciones concretas, que suponen una mejora técnica indudable en relación con el Proyecto de Ley de 1995, tampoco fueron objeto de especial discusión durante los debates parlamentarios. Así, únicamente el proyecto de ley, que sí que experimentó alguna modificación en este sentido en los trámites de carácter prelegislativo, fue modificado por la aceptación de las enmiendas núm. 22 del Grupo Popular y núm. 48 del Grupo Parlamentario de Coalición Canaria, que supusieron una modificación del inciso final del artículo 21.2, mediante la supresión de la referencia a las limitaciones establecidas en la Constitución, ya que ésta no establecía ninguna, indicando únicamente que el Gobierno cesante continúa en funciones hasta la toma de posesión del nuevo Gobierno. Asimismo, y mediante la aceptación de la enmienda núm. 29 del Grupo Parlamentario Catalán, se modificó el artículo 21.5.b), en el sentido de contemplar la posibilidad de presentar proyectos de ley al Senado.

Hasta ahora, la doctrina española, en base únicamente a la Constitución, se mostraba de acuerdo respecto al hecho de que el mantenimiento automático de las funciones ex artículo 101.2 de la Constitución modificaba el status jurídico del Gobierno, pero no así en relación a las competencias concretas a que se extiende la prorrogatio ni en lo que afectaba a la naturaleza de los limites.

Un primer grupo de autores se decantaba por una interpretación gramatical del artículo $\mathbf{1 0 1 . 2}$ indicando que la referencia a la continuidad de funciones del Gobierno cesante lo es a la totalidad de las que la Constitución otorga al Gobierno. 
En este sentido, ALZAGA ${ }^{17}$, tras constatar que en la práctica la actuación del Gobierno en funciones suele limitarse a la gestión de los asuntos de trámite y a garantizar la continuidad de la función administrativa, señala que de iure «(...) puede ejercer la totalidad de las funciones políticas y juridicas que corresponden al Gobierno».

Por su parte, SÁNCHEZ AgESTA ${ }^{18}$ constata la ausencia de límites en la regulación de la prórroga de las funciones gubernamentales, aunque matiza su postura en el caso de que el cese venga producido por pérdida de la confianza parlamentaria: «(...) el Gobierno cesante por pérdida de la confianza sólo puede ser un gobierno que resuelva asuntos de trámite, y si esa situación se prolonga no cabe pensar, por ejemplo, que el presidente proponga nombramiento o separación de ministros o presente Proyectos de Ley (...)».

Dentro de un segundo grupo de autores, podemos incluir a aquellos que, sin pronunciarse acerca de la naturaleza de los límites, enmarcan la actividad del Gobierno en funciones en determinados contornos, excluyendo en todo caso algunas funciones y competencias, cuyo ejercicio quedaría reservado al Gobierno en plenitud de atribuciones.

Este supuesto es el que contempla SANTAOLALLA ${ }^{19}$, para el que hay dos conceptos que delimitan la situación del gobierno en funciones: los asuntos corrientes o de ordinaria administración y los asuntos de carácter urgente: el Gobierno podrá adoptar las decisiones que le correspondan en cuanto órgano administrativo, en cambio debe abstenerse de adoptar iniciativas que impliquen una elección en función de la composición del Gobierno dimisionario o que puedan comprometer seriamente la actuación política de los sucesivos Gobiernos.

Similares consideraciones realizan otros autores (EsPíN, LUCAS Murillo de la CuEva...), que se esfuerzan, tanto en circunscribir el ámbito de actuación a los asuntos ordinarios o de trámite y a los urgentes, como en excluir determinadas competencias (capacidad para plantear la cuestión de confianza o ejercer el derecho de disolución o la de adoptar decisiones políticas que trasciendan a la ordinaria gestión).

17 ALZAGA VILAAMIL, Óscar: Comentario sistemático a la Constitución española de 1978, Madrid, 1978.

18 SAinchez Agesta, Luis: Sistema politico de la Constitución española de 1978, Madrid (2.2 ed.), 1981.

19 Santiolalla López, Fernando: Comentarios a la Constitución (Fernando Garrido Falla), Madrid, 1980. 
Por su parte, Aguiar de LuQue empieza afirmando que «(...) en el régimen parlamentario que diseña la Constitución española no hay razones de principio para entender jurídicamente restringido el ámbito de posibilidades de actuación del gobierno cesante, que es así un Gobierno en plenitud jurídica de facultades, con la salvedad de estar su actuación sometida a un término o plazo, la toma de posesión del nuevo Gobierno». No obstante, con posterioridad puntualiza esa afirmación, indicando que existen dos competencias del Gobierno que, por situarse en el ámbito de la relación de confianza, sí que parece necesario restringirlas para el Gobierno cesante:

- de un lado, señala el planteamiento de la cuestión de confianza y la disolución de las Cámaras, pues transformado un Gobierno ordinario en Gobierno cesante, es decir, rota la relación de fiducia de aquel nexo a través de una investidura explícita, no es posible admitir que un Gobierno cesante pueda acometer la disolución de las Cámaras o el planteamiento de una cuestión de confianza;

- de otro, la imposibilidad de emplear los mecanismos ordinarios de control (preguntas, interpelaciones, etc.), o, al menos, que tales mecanismos no pueden ser utilizados por el pleno del Congreso de los Diputados; el problema se desplaza entonces a la capacidad de controlar el Gobierno en funciones por la Diputación Permanente.

Un tercer grupo de autores se pronuncia por la existencia de límites de carácter jurídico deducibles del propio texto constitucional. SATrústegui y García Herrera, seguidores ambos de la doctrina italiana, señalan que la forma de gobierno parlamentaria implica por principio un límite taxativo a las competencias del Gobierno en funciones.

En este sentido, SATRústegui, además de señalar dos normas de cortesía constitucional a las que en todo caso debería atender el Gobierno cesante como criterios rectores para su actuación (el Gobierno cesante debe abstenerse de actuar cuando surjan dudas acerca de si la medida concreta excede del ámbito de la tutela de los intereses generales y que cuando la urgencia u otras circunstancias induzcan al Gobierno cesante a actuar, éste lo haga en tales términos que prejuzguen lo menos posible la solución final del problema), cifra en la imposibilidad de proseguir el desarrollo del programa de gobierno y en la obligación de tutelar los intereses generales los límites genéricos, estableciendo además una serie de competencias cuyo ejercicio le está vedado al gobierno en situación de prorrogatio. 
Además, existe un punto de casi general acuerdo en la doctrina actual: a priori, se puede realizar un juicio acerca de la oportunidad de las medidas tomadas por el Gobierno en funciones a través del control preventivo del Consejo de Estado, como se indica en el artículo 2.1 de su Ley Orgánica ${ }^{20}$; sin embargo, los límites del Gobierno cesante se configuran como verdaderas limitaciones jurídicas, lo que comporta la nulidad de aquellos actos gubernamentales que rebasan esos ambiguos límites, nulidad, que llegado el caso, puede ser declarada incluso en sede jurisdiccional.

En todo caso, se pueden predicar los mecanismos ordinarios de control en sede parlamentaria (preguntas, mociones, interpelaciones, etc.) y el sistema de controles pertinentes en relación a los decretos legislativos y los decretos-leyes, que establece la propia Constitución.

Como ha indicado D'Orazio ${ }^{21}$, al defender la naturaleza jurídica de los límites se pretende encontrar «un criterio de certidumbre y garantía que se imponga al órgano político con el fin de preservar el criterio de otras posibles mayorías, cuya actuación no debe ser comprometida ni limitada por quien ya no ostenta título de legitimación ni responsabilidad plena de gobierno $y$, en consecuencia, carece de libertad de fines».

Por tanto, se debe destacar cómo en la nueva Ley, a diferencia del Proyecto de Ley de octubre de 1995, se diferencia entre aquellas funciones que no puede ejercer el Presidente del Gobierno de las del Gobierno, indicándose expresamente en su apartado 4 las decisiones que no pueden ser adoptadas por el Presidente del Gobierno en funciones, respetándose así el tenor literal de la Constitución, que atribuye esa competencia al Presidente, de forma específica, y no al Gobierno. Por tanto, no se limita este artículo a establecer un principio general, sino que establece límites concretos a las funciones que pueden desempeñar tanto el Presidente como su Gobierno.

${ }^{20}$ Artículo 2.1 de la Ley Orgánica 3/1980, de 22 de abril, del Consejo de Estado:

"En el ejercicio de la función consultiva el Consejo de Estado velará por la observancia de la Constitución y del resto del ordenamiento juridico. Valorara los aspectos de oportunidad y conveniencia cuando lo exijan la indole del asunto o lo solicite expresamente la autoridad consultante, asi como la mayor eficacia de la Administración en el cumplimiento de sus fines."

${ }^{21}$ D'Orazio, Giustino: «Prorrogatio (diritto costituzionale)», en Enciclopedia del Diritto, vol. XXXVI, Milano, 1988. 